\title{
BUOYANT TITRATION OF OVALBUMIN IN FOUR ALKALI HALIDES. HYDRATION AND ION BINDING
}

\author{
by \\ TORBEN GRAVES PEDERSEN \\ and \\ JAMES B. IFFT' \\ Department of Chemistry, Carlsberg Laboratory, \\ Gamle Carlsberg Vej 10, DK-2500 Copenhagen, Valby \\ 1. Permanent address: Department of Chemistry, University of Redlands, Redlands, California 92373, U.S.A.
}

Keywords: Ultracentrifugation, bouyant density, protein

The buoyant titrations of ovalbumin in $\mathrm{CsCl}, \mathrm{RbCl}, \mathrm{CsBr}$ and $\mathrm{RbBr}$ were measured between $\mathrm{pH} 2$ and 13 . The buoyant densities were found to depend on the salt employed to generate the density gradient and the solution $\mathrm{pH}$. At low $\mathrm{pH}$, nearly identical buoyant densities were observed in solutions having a common anion while at high $\mathrm{pH}$, salt solutions having the same cation produced nearly indentical buoyant densities. The buoyant density of ovalbumin in $\mathrm{RbBr}$ was found to decrease as the $\mathrm{pH}$ was increased from 2 to 6 . This is the first demonstration of a drop in the buoyant titration curve for a biopolymer.

A model based on an invariant partial specific volume, normal titration of all amino acid residues, the binding of a counter-ion to each ionized residue and all hydration associated with these salt pairs was constructed and satisfactorily accounted for all four buoyant titration curves. These results indicate that no water is bound to the neutral portion of this protein.

\section{INTRODUCTION}

Several studies of native and chemically modified proteins in density gradients at sedimentation equilibrium in the analytical ultracentrifuge have been reported $(22,9,4,19$, 16, 23). These investigations report the buoyant density as a function of $\mathrm{pH}$. A buoyant density is defined as the density of the solvent in a gradient column corresponding to the center of the polymer band at equilibrium. All buoyant titrations reported to date have employed $\mathrm{CsCl}$ as the solute to generate the density gradient. In these solutions, all proteins studied thus far have displayed increases in density as the amino acid residues titrate. These increases occur at about $\mathrm{pH} 4$ as the aspartic and glutamic acids titrate and around $\mathrm{pH} 10$ as the lysines, tyrosines and cysteines are deprotonated. These increments have been interpreted in terms of a model involving the binding and release of hydrated cesium and chloride ions.

Buoyant titrations of ovalbumin in three additional salts, $\mathrm{CsBr}, \mathrm{RbBr}$ and $\mathrm{RbCl}$, were measured in this investigation in order to compare the results in this anion-cation series with those already obtained in $\mathrm{CsCl}(9)$. It was hoped that these studies would provide insights into the kind of model which is necessary to explain buoyant titration curves and hence the nature of ion-binding and hydration in proteins. 


\section{LIST OF SYMBOLS}

$\rho_{0}^{\circ} \quad$ buoyant density of ovalbumin before pressure correction, $\mathrm{g} / \mathrm{m}$ l

$\rho_{\mathrm{e}}^{\circ} \quad$ initial density of the salt solution, $\mathrm{g} / \mathrm{ml}$

$\rho_{\mathrm{o}}^{\mathrm{o}}-\rho_{\mathrm{e}}^{\mathrm{o}}$ distance from the isoconcentration point of the cell to the ovalbumin band at equilibrium

Po buoyant density of ovalbumin after pressure correction, $\mathrm{g} / \mathrm{ml}$

$T$ total hydration of the ovalbuminsalt complex, moles water/mole protein

$\mathrm{n}_{\mathrm{c}}$ moles cations bound/mole ovalbumin

$n_{a} \quad$ moles anions bound/mole ovalbumin

$\mathrm{M}_{\mathrm{c}} \quad$ weight of 1 mole cations, $\mathrm{g} / \mathrm{mole}$

$\mathrm{M}_{\mathrm{a}} \quad$ weight of 1 mole anions, $\mathrm{g} /$ mole

$\mathrm{M}_{\mathrm{H}_{2} \mathrm{O}} \quad$ mole weight of water

$M_{p} \quad$ mole weight of ovalbumin, 45000 $\mathrm{g} /$ mole, excluding moles salt and water

$\overline{\mathbf{V}}_{\mathrm{p}} \quad$ partial molar volume of ovalbumin $(45000 \times 0.748 \mathrm{ml} / \mathrm{mole})$

$\overline{\mathrm{V}}_{\mathrm{c}} \quad$ partial molar volume of the cation, $\mathrm{ml} / \mathrm{mole}$

$\overline{\mathrm{V}}_{\mathrm{a}} \quad$ partial molar volume of the anion, $\mathrm{ml} / \mathrm{mole}$

$\overline{\mathrm{V}}_{\mathrm{H}_{2} \mathrm{O}} \quad$ partial molar volume of water

$\mathrm{aa}^{-} \mathrm{Cs}^{+}$charge-ion complex composed of the negative charge from an amino acid residue (only the charge) and the bound cesium ion

$\mathrm{aa}^{-} \mathrm{Rb}^{+}$negative charge-rubidium ion complex

$\mathrm{aa}^{+} \mathrm{Cl}^{-}$positive charge-chloride ion complex

$\mathrm{aa}^{+} \mathrm{Br}^{-}$positive charge-bromide ion complex
G hydration of a charge-ion complex, moles water/mole complex

W the weight of a hydrated charge-ion complex, $\mathrm{g} /$ mole

the volume of a hydrated charge-ion complex, $\mathrm{ml} /$ mole

$a_{1} \quad$ water activity

$\mathrm{H}$ hydration of a charge-ion complex at $\mathrm{a}_{1}=1$

$\alpha \quad$ slope of $G$ vs $a_{1}$

$\nu$ number of ionized state from one mole electrolyte

$\mathrm{m}_{2} \quad$ molality of electrolyte

$\Phi$

osmotic coefficient

\section{MATERIALS AND METHODS \\ 3.1. Materials}

The ovalbumin employed in this study was obtained from a sample prepared in the Carlsberg Laboratory in 1965 from hens' eggs according to procedure of SøRENSEN (20). This is the same preparation used in the earlier studies of ovalbumin in $\mathrm{CsCl}$ (9). It had been stored at $4{ }^{\circ} \mathrm{C}$ as crystals in saturated $\left(\mathrm{NH}_{4}\right)_{2} \mathrm{SO}_{4}$ with a layer of toluene on the surface to prevent bacterial contamination. It was recrystallized and exhaustively dialyzed against deionized water before use.

The $\mathrm{CsCl}$ was obtained from the Pierce Chemical Co., Rockford, Illinois. It was product number 1115-470 and stated to be 99.9\% pure. The $\mathrm{RbCl}, \mathrm{CsBr}$ and $\mathrm{RbBr}$ were obtained from E. Merck, Darmstadt, and were of Suprapur quality.

All buffers were of reagent quality.

\subsection{Amino acid analysis}

In order to check on the purity of the ovalbumin $24 \mathrm{~h}$ acid hydrolyses were made in $6 \mathrm{M}-\mathrm{HCl}$ in sealed, evacuated tubes and the amino acid analyses performed on a Durrum, Model 500. Runs were conducted with buffers of $\mathrm{pH} 3.25,4.25$ and 7.90 . 


\subsection{Absorption measurements}

were performed with a Cary 118 recording spectrophotometer. Concentrations of ovalbumin solutions were calculated using

O.D. $\underset{280 \mathrm{~nm}}{0.1 \%, 1 \mathrm{~cm}}=0.73$.

\subsection{Refractive indices}

were measured on a Hilger refractometer. The prisms were held at $25.0 \pm 0.1^{\circ} \mathrm{C}$ by a Heto circulating bath. All $\mathrm{n}_{\mathrm{D}^{25}}$ values were corrected for the contribution of the protein. Refractive indices were measured before and after every run. All determinations were reproducible within \pm 0.0001 .

\section{5. pH measurements}

were made with a Radiometer $\mathrm{pH}$ meter, model PHM63 equipped with a combination electrode. Standardization of the instrument was made with Radiometer Standard Buffers.

The $\mathrm{pH}$ was measured before and after every run. A shift towards neutral $\mathrm{pH}$ for solutions with high and low initial pH's was observed during the experiments. The changes observed were between 0 and $0.2 \mathrm{pH}$ units. The tabulated $\mathrm{pH}$ values are the average of the initial and final pH's. Buffer concentrations varied between 0.01 and $0.04 \mathrm{M}$. To bring the alkali halide solutions containing ovalbumin to low and high $\mathrm{pH}, \mathrm{HCl}$ and $\mathrm{CsOH}$ respectively were used. The $\mathrm{pH}$ values near 10 were obtained with a glycine buffer, while the $\mathrm{pH}$ values near 6 were obtained by titration to this $\mathrm{pH}$ and utilizing the buffering capacity of the ovalbumin. It is assumed that these buffer concentrations are so low in comparison with the approximately $2.5 \mathrm{M}$ concentrations of salt that they will have a negligible effect on either the density gradients or the binding properties of ovalbumin.

\subsection{Ultracentrifuge measurements}

were performed in a Spinco Model E ultracentrifuge using the schlieren optics. An An$D$ rotor was used in conjunction with standard $12 \mathrm{~mm}$ Kel-F centerpieces and $0^{\circ},-1^{\circ}$ and $-2^{\circ}$ wedge windows. The temperature was kept at $25.0 \pm 0.1^{\circ} \mathrm{C}$ and the angular velocity was 44770,52640 or 59780 revolutions per minute. The alkali halide solutions containing ovalbumin were prepared following standard procedures (8). Buoyant densities in each of the four salts were measured at $\mathrm{pH}$ 's close to 2,6 , 10 and 12.

\subsection{Analyses}

Equilibrium was found to be reached in 16 hours. After this time, photographs were taken using Kodak metallographic plates. After development, enlarged prints, ca. $20 \times 20 \mathrm{~cm}$, were made. The print was placed upside down on a light table and the salt gradient curve, its intersection with the protein band (the position corresponding to the buoyant density of the protein) and the meniscus, bottom and reference positions were easily and precisely located with a sharply pointed pencil. After the light was turned off, the distances from the reference line provided by the reference hole in the rotor to the other positions in the cell were measured.

\section{Calculations}

\subsection{Buoyant densities}

Buoyant densities were evaluated by means of Eq. [3] of IFFT (9). This relation requires the slope of the density gradient proportionality constant, $\beta$, vs. density, $p$, curve. These data are available for $\mathrm{CsCl}$ (9) but have not been measured for the other three salts. Large scale plots of the published $\beta(p)$ data (10) were made and slopes measured at intervals of 0.05 units. These data (which will be provided in a compilation to be published soon) were stored in a computer memory file along with the appropriate refractive index and $\beta(\rho)$ data arrays.

A program was written in FORTRAN for a Honeywell Bull computer utilizing Eq. [3] of reference (9) to compute the isoconcentration position. Because some of the bands formed as much as 0.06 density units away from this position and because the $\beta(\rho)$ are sharply falling in this density region, a step-wise calculation 
was made starting at the isoconcentration position in increments of $0.0005 \mathrm{~cm}$. New $\beta$ values were computed at each new cell position and density by linear interpolations within the $\beta(\rho)$ data file. This method provides data as accurate as that provided by the recently published Eq. [5] of reference (18) for computation of density distributions although a somewhat larger computer memory is required. Copies of this program may be obtained by writing the Carlsberg Laboratory.

\subsection{Water activities}

Water activities, $a_{1}$, were computed at each buoyant concentration in each of the four salt solutions from the standard relation

$$
\text { ln } a_{1}=\frac{-v m_{2}{ }_{H_{2}} O}{1000} \text {. }
$$

Values of the osmotic coefficient, $\Phi$, were obtained from RoBINSON and STOKES (15).

\section{RESULTS}

\subsection{Amino acid analyses}

The amino acid composition of the ovalbumin sample was found to be identical to that obtained in the $\mathrm{CsCl}$, buoyant titration study (9).

\subsection{Buoyant titration data}

These data are presented in Table I and Figure 1. Column 4 of Table I presents the difference in density between the buoyant density and the original solution density. This provides a measure of how far away from the isoconcentration position the ovalbumin banded and hence how many steps were required in the computer program. Column 7 gives the observed buoyant densities of the soluble bands and that of the precipitated bands when present.

The actual buoyant densities determined in this study are given by the points on the several curves in Figure 1. The curve connecting the two points measured in $\mathrm{CsCl}$ was constructed

Table I

Density gradient experiments with ovalbumin.

\begin{tabular}{|c|c|c|c|c|c|c|c|}
\hline \multirow[b]{2}{*}{ Run no. } & \multirow[b]{2}{*}{ rpm } & \multirow[b]{2}{*}{ hrs } & \multirow[b]{2}{*}{$\rho_{\mathrm{o}}^{\mathcal{O}}-\rho_{\mathrm{e}}^{\mathcal{O}}$} & \multirow[b]{2}{*}{ salt } & \multirow[b]{2}{*}{$\mathrm{pH}$} & \multicolumn{2}{|c|}{ Byoyant Densities } \\
\hline & & & & & & soluble & precipitate \\
\hline C1196-0 & 52640 & 21 & 0.001 & $\mathrm{CsCl}$ & 1.9 & 1.264 & 1.274 \\
\hline C1195-0 & 52640 & 22 & 0.012 & & 13.0 & 1.342 & \\
\hline $\mathrm{C} 1205-0$ & 52640 & 22 & -0.003 & $\mathrm{RbCl}$ & 1.9 & 1.271 & 1.284 \\
\hline C1209-1 & 59780 & 19 & 0.014 & & 2.9 & 1.270 & 1.288 \\
\hline C1206-0 & 52640 & 20 & 0.010 & & 5.9 & 1.291 & \\
\hline C1207-0 & 52640 & 21 & 0.019 & & 10.0 & 1.296 & \\
\hline C1208-0 & 52640 & 18 & 0.047 & & 12.7 & 1.317 & \\
\hline C1209-0 & 59780 & 19 & 0.024 & & 12.9 & 1.319 & \\
\hline C1212-1 & 44770 & 21 & 0.013 & $\mathrm{CsBr}$ & 2.0 & - & 1.320 \\
\hline $\mathrm{Cl} 1210-1$ & 44770 & 22 & -0.024 & & 3.0 & 1.311 & 1.320 \\
\hline $\mathrm{C} 1211 \cdot 1$ & 44770 & 21 & -0.061 & & 5.9 & 1.321 & \\
\hline C1211-0 & 44770 & 21 & -0.057 & & 9.7 & 1.322 & \\
\hline $\mathrm{C} 1210-0$ & 44770 & 22 & 0.058 & & 12.2 & 1.340 & \\
\hline $\mathrm{C} 1212-0$ & 44770 & 21 & 0.025 & & 12.9 & 1.340 & \\
\hline $\mathrm{C} 1216-1$ & 52640 & 21 & - & $\mathrm{RbBr}$ & 1.8 & - & $\begin{array}{l}1.320 \\
1.325\end{array}$ \\
\hline C1215-1 & 52640 & 17 & -0.001 & & 3.5 & 1.308 & $\begin{array}{l}1.318 \\
1322\end{array}$ \\
\hline C1217-1 & 52640 & 21 & 0.004 & & 5.3 & 1.304 & \\
\hline $\mathrm{C} 1217-2$ & 52640 & 21 & 0.005 & & 9.4 & 1.306 & \\
\hline C1215-2 & 52640 & 17 & -0.002 & & 12.1 & 1.309 & \\
\hline $\mathrm{C} 1216-2$ & 52640 & 21 & 0.014 & & 13.1 & 1.310 & \\
\hline
\end{tabular}




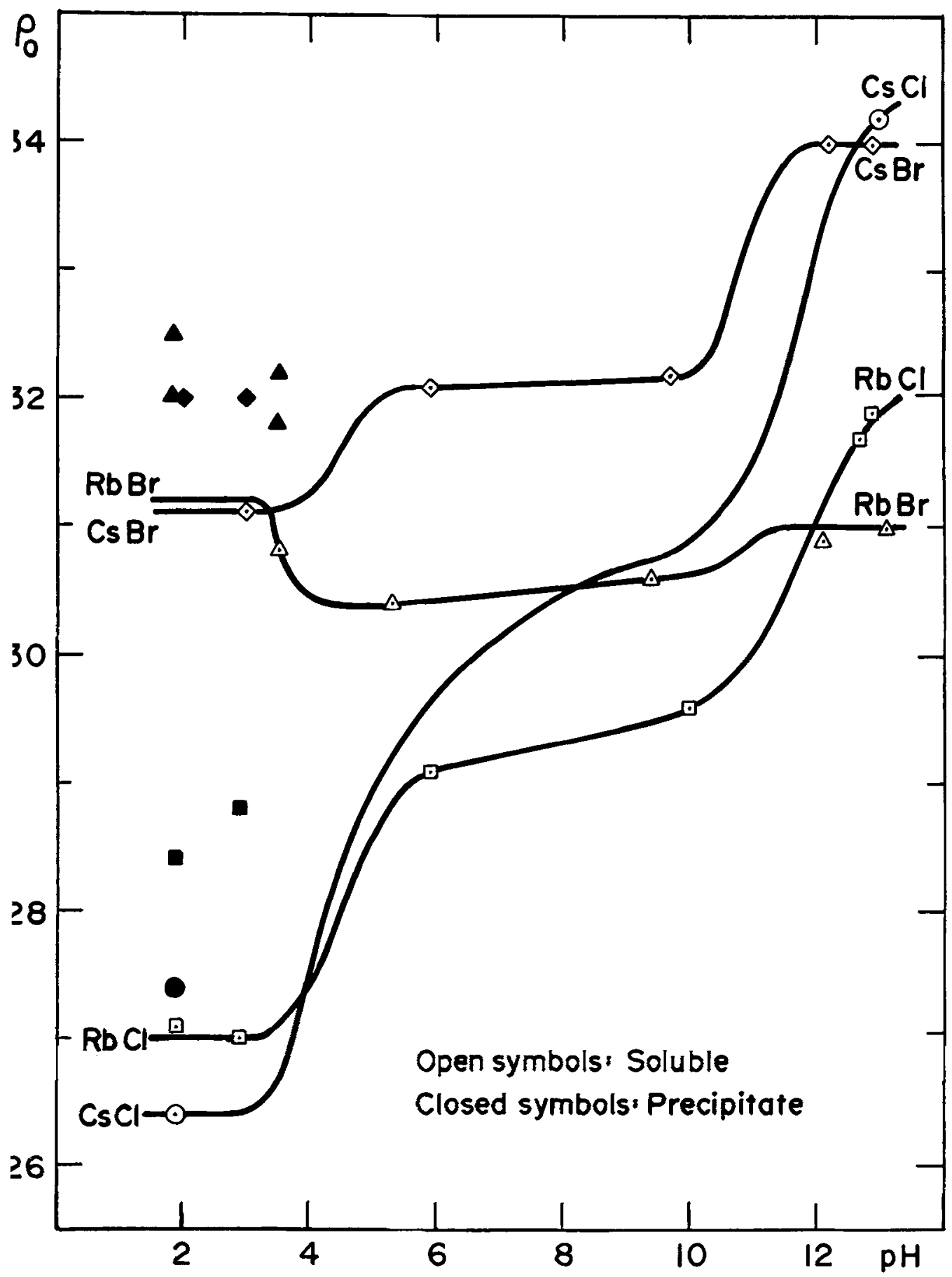

Figure 1. The buoyant titrations of ovalbumin in four salt solutions. 
from the earlier $\mathrm{CsCl}$ buoyant titration (9). The curves for the other three salts were constructed from the six new data points with the assumption that the inflections occurred at about the same $\mathrm{pHs}$ as observed for $\mathrm{CsCl}$.

As indicated in Figure 1, both soluble and precipitated bands were observed in $\mathrm{CsCl}$ and $\mathrm{RbCl}$ at both $\mathrm{pH} 2$ and $\mathrm{pH} 3$. However, insoluble bands only were observed at $\mathrm{pH} 2$ in $\mathrm{CsBr}$ and $\mathrm{RbBr}$. Because of the constant $\triangle \rho$ observed in all salt solutions between the precipitated and soluble bands, the soluble buoyant densities in the two bromide salts were estimated from the two observed precipitated bands.

At low $\mathrm{pH}$, the buoyant densities of ovalbumin in salts sharing a common anion are similar. At high $\mathrm{pH}$, a similar situation is observed for salts with the same cation. In the $\mathrm{pH}$ region from 6 to 9 , the buoyant densities of ovalbumin increased slightly in the chloride salts and were almost constant in the bromide salts.

\section{DISCUSSION}

In Table II, the buoyant densities of ovalbumin in $\mathrm{CsCl}, \mathrm{RbCl}, \mathrm{CsBr}$ and $\mathrm{RbBr}$ estimated from Figure 1 at the $\mathrm{pH}$ values 2, 8.5 and 13 , and the corresponding water activities $\mathrm{a}_{1}$, are presented. The $\mathrm{pH}$ values $2,8.5$ and 13 are chosen because Table III indicates that none of the ovalbumin amino acid residues titrate at these pH's. This is important because the numbers of positive and negative charges on ovalbumin are employed in the following calculations. The water activities are calculated

Table II

Buoyant densities of ovalbumin as a function of $\mathrm{pH}$ and sait. $\mathrm{a}_{1}$ is the water activity of a salt solution with the same buoyant density.

\begin{tabular}{lcccccccc}
\hline Salt & \multicolumn{2}{c}{$\mathrm{CsCl}$} & \multicolumn{2}{c}{$\mathrm{RbCl}$} & \multicolumn{2}{c}{$\mathrm{CsBr}$} & \multicolumn{2}{c}{$\mathrm{RbBr}$} \\
\hline $\mathrm{pH}$ & $\rho_{0}$ & $\mathrm{a}_{1}$ & $\rho_{0}$ & $\mathrm{a}_{1}$ & $\rho_{0}$ & $\mathrm{a}_{1}$ & $\rho_{0}$ & $\mathrm{a}_{1}$ \\
\hline 2 & 1.264 & .929 & 1.270 & .886 & 1.311 & .937 & 1.312 & .912 \\
8.5 & 1.306 & .916 & 1.295 & .872 & 1.322 & .934 & 1.305 & .914 \\
13 & 1.342 & .905 & 1.320 & .860 & 1.340 & .930 & 1.310 & .912 \\
\hline
\end{tabular}

Table III

Ionizable groups of ovalbumin and their approximate $\mathbf{p} \mathbf{K}_{\mathbf{A}}$ 's ${ }^{\dagger}$.

\begin{tabular}{rlc}
\hline number & group & $\mathrm{pK}_{\mathrm{A}}$ \\
\hline 1 & $\alpha-\mathrm{COOH}$ & 3.6 \\
51 & asp+glu & 4.4 \\
$* 2$ & phosphate & 7 \\
7 & his & 7 \\
1 & $a-\mathrm{NH}_{2}$ & 7.6 \\
5 & cys & 9.5 \\
20 & lys & 10 \\
10 & tyr & 10 \\
2 & phosphate & 12 \\
15 & arg & $>12$ \\
\hline
\end{tabular}

$\uparrow$ Data from reference (10).

* The phosphorus content of the crystalline material is somewhat variable. Values of 1.75 to 1.89 atoms for $45.000 \mathrm{~g}$ have been reported (11). In this paper, we assume 2 phosphorus atoms. 
because several authors $(3,8)$ have found that the hydration of polymers depends on the salt concentration in the solutions. Water activity is the best measure to compare results in solutions of different salts.

Of the 379 amino acid residues in ovalbumin, 110 are ionizable. It is assumed that all ionizable residues in ovalbumin in the salt solutions used in this study titrate with normal pK's (13), (Table III). This implies that ovalbumin at $\mathrm{pH} 2$ has 43 positively charged amino acid residues comprising 15 arginines, 20 lysines, 7 histidines and one primary amino group. Going to $\mathrm{pH} 6,52$ carboxyl groups titrate. From pH 6 to 8.5 the 7 histidines, the primary amino group and the 2 phosphate groups titrate. From pH 8.5 to 13 , the lysines, tyrosines, cysteines and the 2 phosphate groups titrate. At $\mathrm{pH} \mathrm{13,} \mathrm{the} \mathrm{only} \mathrm{charged} \mathrm{groups} \mathrm{are}$ the 15 positively charged arginines and the negatively charged carboxyl, phenoxide, sulfide and phosphate groups.

Table IV presents the variation of charge dis-

\section{Tabel IV}

Charged groups of ovalbumin as a function of $\mathrm{pH}$.

\begin{tabular}{ccc}
\hline & \multicolumn{2}{c}{ Amino Acid Residues } \\
pH & positive & negative \\
\hline 2 & 43 & 0 \\
8.5 & 35 & 54 \\
13 & 15 & 71 \\
\hline
\end{tabular}

tribution on ovalbumin with $\mathrm{pH}$. To maintain neutrality, each ionized amino acid residue is assumed to bind an oppositely charged salt ion. For example at $\mathrm{pH} 8.5$, ovalbumin is assumed to bind $35 \mathrm{Br}^{-}$and $54 \mathrm{Rb}^{+}$in $\mathrm{RbBr}$ solution.

All the assumptions employed in the following calculations are summarized below:

1. The partial specific volume of the ovalbumin charged species is constant, $0,748 \mathrm{ml} / \mathrm{g}$, over the $\mathrm{pH}$ range and in the salt solutions studied.

2. Ionizable amino acid residues in ovalbumin titrate with the $\mathrm{pK}_{\mathrm{A}}$ values given in Table III. Arginines are believed to be positively charged at $\mathrm{pH} 13$.

3. Each ionic charge on the protein binds an oppositely charged salt ion.

4. The density of water, both bulk and bound, has the value $1.000 \mathrm{~g} / \mathrm{ml}$.

5. The loss of a proton will have no effect on the buoyant density of ovalbumin.

6. The neutral part of ovalbumin does not bind water. All of the bound water is bound to the ionized amino acid residues and their counter ions.

\subsection{Definition of charge-ion complex}

We define a charge-ion complex as the charge on an ionized amino acid plus the bound oppositely charged salt ion. The hydration, G, of this complex is the number of water molecules bound to the charge and the salt ion.
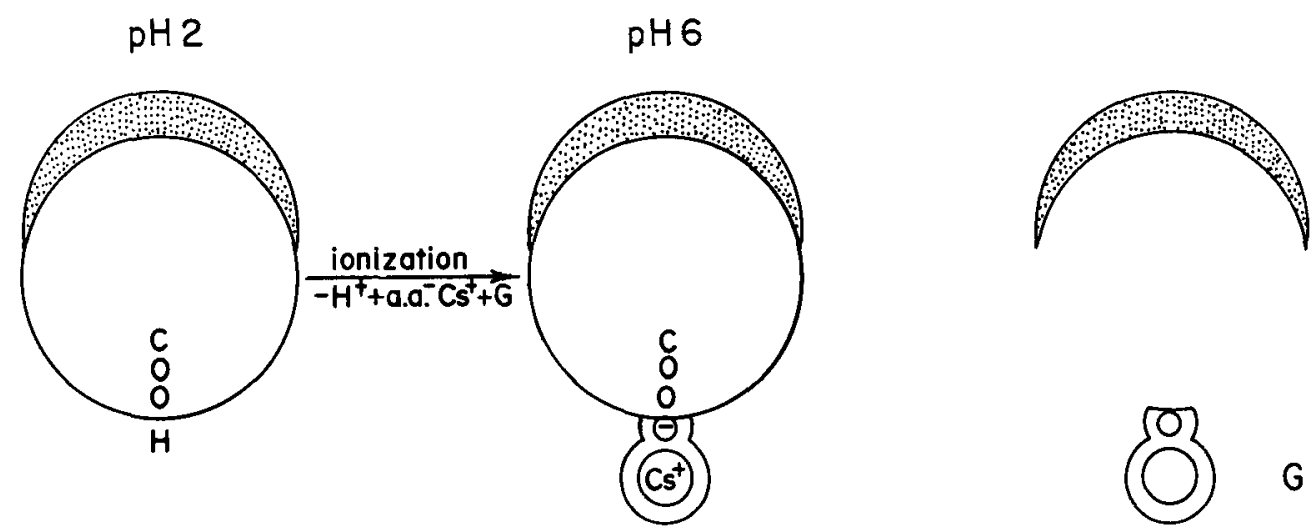

Figure 2. The hydration change due to ionization of a carboxylic acid in ovalbumin. $B$ is the water bound to the neutral part of the protein and $G$ is the amount of water bound to the charge-ion complex. 
The expression $\mathrm{aa}^{-} \mathrm{Cs}^{+}$is used for the chargeion complex of a negative charge from an amino acid residue and a positive cesium ion (see Figure 2).

\subsection{Total hydration of ovalbumin}

The total number of water molecules, $\mathrm{T}$, physically bound to ovalbumin at a certain $\mathrm{pH}$ and in a particular salt can be calculated according to SHARP et al. (17) from equation [2] using the measured buoyant densities, $\rho_{\mathrm{o}}$. Table $\mathrm{V}$ presents the calculated $\mathrm{T}$ values.

$$
\frac{M_{p}+n_{c} M_{c}+n_{a} M_{a}+T_{H_{2} O} O}{\bar{v}_{p}+n_{c} \bar{v}_{c}+n_{a} \bar{v}_{a}+T_{H_{2}} O}=p_{0}
$$

This quantity, $T$, corresponds to the $B_{1}$ term recently discussed by EISENBERG (14). T and $B_{1}$ are synonomous provided that $B_{3}-E_{3}$ equals zero in the EISENBERG model. $B_{3}$ is the salt binding and $E_{3}$ is the Donnan electrostatic exclusion of salt.

\subsection{Calculation of hydration of charge-ion com- plexes}

Ionization of an amino acid residue creates a charged group with concomitant loss of a proton. It is assumed that this will have no in- fluence on the density. The change in buoyant density is due to the binding of a counter ion to the ionized amino acid residue and bound water associated with the charge-ion complex. The hydration values, $G$, of the charge-ion complexes of ovalbumin can now be determined.

The sequence of calculations utilized in this analysis begins with the data in the four salt solutions at $\mathrm{pH} 2$. The charge on ovalbumin here consists of 43 positively charged groups and no negative charges. Thus, $T$ can be computed from Equation [2] using $n_{c}=0$ and $n_{a}=$ 43. Values of $G$ are then obtained by dividing $T$ by 43 . These four hydrations, two for each charge-anion complex, $\mathrm{aa}^{+} \mathrm{Cl}^{-}$and $\mathrm{aa}^{+} \mathrm{Br}^{-}$, are presented in the first line of Table VI. The two values of $G$ are plotted as a function of water activity in Figure 3 and the dependence is assumed to be linear.

Hydrations were then computed at higher $\mathrm{pH}$ values based upon the above results. Values of T were computed from Equation [2] for each of the four salts at $\mathrm{pH}$ values of 8.5 and 13 . Values of $n_{c}$ and $n_{a}$ were selected to satisfy the charged groups on the protein as tabulated in Table IV. Hydrations of the charge-anion complexes were determined at the water activity corresponding to each buoyant density by correlating the data of Table II and Figure 3.

Tabel V

Number of water molecules, $T$, bound to the ovalbumin-salt complex in different salts at different pH values.

\begin{tabular}{ccccc}
$\mathrm{pH}$ & $\mathrm{CsCl}$ & $\mathrm{RbCl}$ & $\mathrm{CsBr}$ & $\mathrm{RbBr}$ \\
\hline 2 & 560 & 503 & 463 & 457 \\
8.5 & 1261 & 982 & 1321 & 1125 \\
13 & 1202 & 941 & 1113 & 1139 \\
\hline
\end{tabular}

Table VI

Hydration of the charge-ion complexes, moles water/mole complex.

\begin{tabular}{ccccccccc}
\hline $\mathrm{pH}$ & \multicolumn{2}{c}{$\mathrm{CsCl}$} & \multicolumn{2}{c}{$\mathrm{RbCl}$} & \multicolumn{2}{c}{$\mathrm{CsBr}$} & \multicolumn{2}{c}{$\mathrm{RbBr}$} \\
\hline & $\mathrm{aa}^{-} \mathrm{Cs}^{+}$ & $\mathrm{aa}^{+} \mathrm{Cl}^{-}$ & $\mathrm{aa}^{-} \mathrm{Rb}^{+}$ & $\mathrm{aa}^{+} \mathrm{Cl}^{-}$ & $\mathrm{aa}^{-} \mathrm{Cs}^{+}$ & $\mathrm{aa}^{+} \mathrm{Br}^{-}$ & $\mathrm{aa}^{-} \mathrm{Rb}^{+}$ & $\mathrm{aa}^{+} \mathrm{Br}^{-}$ \\
\hline 2 & & 13.0 & & 11.7 & & 10.8 & & 10.6 \\
13 & 15.1 & 12.6 & 10.9 & 11.3 & 17.5 & 10.8 & 13.9 & 10.6 \\
13 & 14.3 & 12.3 & 11.0 & 10.9 & 16.2 & 10.8 & 13.8 & 10.6 \\
\hline
\end{tabular}




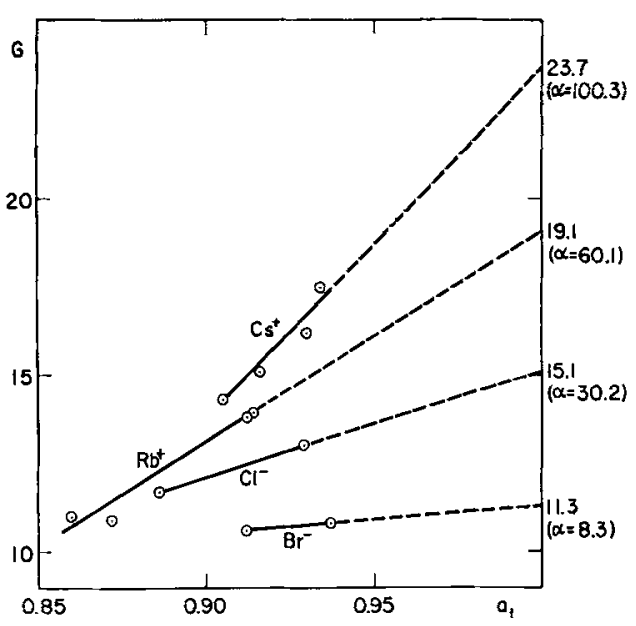

Figure 3. Moles water per mole charge-ion complex vs. water activity.

The water bound to the charge-cation complexes could then be readily computed as the difference between the total amount of water bound, $\mathrm{T}$, and that bound to the charge-anion complexes. Thus, four values were obtained for each cation at different water activities. These values for the charge-cation groups are also tabulated in Figure 3 and Table VI.

Figure 3 demonstrates that the total hydration of all of the charge-ion complexes increases as the water activity increases. Or conversely, the total amount of water bound increases as the salt concentration decreases.

\subsection{Estimation of the hydration of the neutral part of ovalbumin}

The assumption that the hydrated water is bound only to the charge-ion complexes can be examined by considering the data for the $\mathrm{pH}$ region in which the carboxyl groups ionize. Between $\mathrm{pH} 2$ and $\mathrm{pH} 6$, all 52 of the carboxyl groups are ionized giving rise to the formation of 52 hydrated charge-cation complexes. From the difference in the buoyant densities at these two $\mathrm{pH}$ 's, the hydrations, $\mathrm{G}$, at $\mathrm{pH} 6$ for $\mathrm{aa}^{-} \mathrm{Cs}^{+}$ were computed to be $14.5\left(a_{1}=0.919\right)$ and 17.0 $\left(a_{1}=0.935\right)$ for $\mathrm{CsCl}$ and $\mathrm{CsBr}$ respectively, and $9.6\left(a_{1}=0.875\right)$ and $13.7\left(a_{1}=0.914\right)$ for $\mathrm{aa}^{-} \mathrm{Rb}^{+}$ in $\mathrm{RbCl}$ and $\mathrm{RbBr}$ respectively. These values are only slightly smaller than the hydrations given in Figure 3 at comparable water activities.

If similar comparisons are valid for the charge-anion complexes as well, this implies that more than $80 \%$ of the total hydration in $\mathrm{RbCl}$ and more than $90 \%$ of the total hydration in $\mathrm{CsCl}, \mathrm{CsBr}$ and $\mathrm{RbBr}$ occurs on the chargeion complexes. Thus, virtually no water is available for hydration of the hydrophobic and uncharged portions of ovalbumin.

\subsection{Calculation of the buoyant titration curves of ovalbumin}

Only one additional set of data is required for the computation of the buoyant titration curves of ovalbumin in these four salts. These data are the weight, $\mathrm{W}$, in $\mathrm{g} /$ mole, and the volume, $\mathrm{V}$, in $\mathrm{ml} / \mathrm{mole}$ of the hydrated charge-ion complex as a function of water activity. The latter computation requires the assumptions of additive volumes and the identity of molar volumes with partial molar volumes. Values of $W$ and $V$ can then be obtained from Equations [3] and [4].

$$
\begin{aligned}
& W=M_{c \text { or } a}+\left(H-\left(1-a_{1}\right) \alpha\right) M_{H_{2}} \mathrm{O} \\
& V=\bar{v}_{c \text { or } a}+\left(H-\left(1-a_{1}\right) \alpha\right) \bar{v}_{\mathrm{H}_{2}} \mathrm{O}
\end{aligned}
$$

In these equations, $\mathrm{H}$ is the number of moles of water per mole of charge-ion complex corresponding to $a_{1}=1$ in Figure 3 and $\alpha$ is the slope of lines in that figure. The resulting $W$ and $V$ values are plotted as a function of water activity in Figure 4.

It is now possible to compute the buoyant densities from the data in Tables IV and Figure 4 and the known molecular weight, $M_{p}$ and partial molar volume, $\overline{\mathrm{V}}_{\mathrm{p}}$

$$
\rho_{0}=\frac{M_{p}+n_{c} w_{c}+n_{a} w_{a}}{\bar{v}_{p}+n_{c} V_{c}+n_{a} V_{a}}
$$

Because the weight and volume data of Table IV were derived from the original buoyant density results, these computed values cannot be regarded as independent calculated values which can be compared with the experimental data as a rigorous test of this model. Nonetheless, such a comparison does provide a check on the internal consistency of these com- 
T. G. PEDERSEN \& J. B. IFFT: Buoyant titration of ovalbumin

Table VII

The buoyant density data for ovalbumin calculated from Equation [5] using Table IV and Figure 4.

\begin{tabular}{ccccc}
\hline $\mathrm{pH}$ & $\mathrm{CsCl}$ & $\mathrm{RbCl}$ & $\mathrm{CsBr}$ & $\mathrm{RbBr}$ \\
\hline 2 & 1.264 & 1.271 & 1.312 & 1.312 \\
8.5 & 1.305 & 1.293 & 1.325 & 1.304 \\
13 & 1.344 & 1.322 & 1.338 & 1.309 \\
\hline
\end{tabular}

putations and also in a measure of the validity of the two assumptions involved in formulating Equation [5].

The results of these calculations are given in Table VII. It is apparent from a comparison of these data with the experimental data of Table II that good agreement exists.

In order to further test the validity of the several assumptions of this model listed in the opening portion of this discussion and to improve its predictive ability, buoyant titrations of other proteins in these four salts will be measured and compared with values computed from Equation [5] and the data in Figure 4.

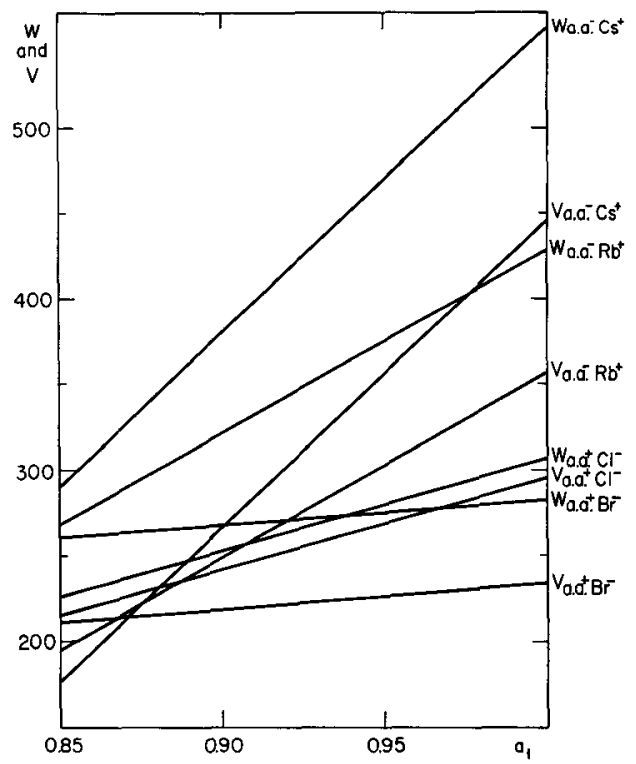

Figure 4. The weight, $\mathrm{W}, \mathrm{g} / \mathrm{mole}$, and the volume, $\mathrm{V}$, $\mathrm{ml} / \mathrm{mole}$, og the hydrated charge-ion complexes as a function of water activity, $a_{1}$.

\subsection{Comparison with other results}

Three aspects of the results of this study can be compared with previously published data. The first comparison deals with the observation that the buoyant densities of ovalbumin at low $\mathrm{pH}$ are similar in salts sharing a common anion. Similarly, the same buoyant densities are observed at high $\mathrm{pH}$ in salts with the same cation. These data suggest that water activity plays a minor role in determining the hydrations at these pH's. This is in good agreement with the results of BULL and BREESE (3) who found that salt and water were bound to the proteins independent of $a_{1}$.

The second comparison is to be made with the previously published studies from Professor HEARST's laboratory $(6,21)$ and the late Professor VINOGRAD's laboratory (7) who showed that the preferential hydration of DNA is a monotorically increasing function of water activity. This result has also been confirmed in a buoyant density titration study of poly-L-Lys and poly-L-His in a preceding article in this volume. The data of Figure 3 of the present study demonstrate an increase in hydration with increasing water activity although the data do not cover a large enough range of $a_{1}$ values to demonstrate with certainty whether this increase is linear or exponential.

Finally, the conclusion that most of the water bound to ovalbumin is bound to the charge-ion complexes can be compared to other results. FALK et al. (5) employed infrared studies, KUNTZ (11) used NMR, and BREUER and KENNERLY (1) utilized isopiestic measurements to show that between 4 and 8 water molecules are bound to each charged site on a variety of biopolymers at relative humidities above $70 \%$. Because none of these studies reports an 
average hydration greater than 3 per residue, the remainder of the residues (the nonpolar groups) can be presumed to bind considerably less water than the ionic groups. The values of 10-20 water molecules per charge-ion complex obtained in the present study are difficult to compare directly with hydrations determined separately for the charged amino acid residue or the bound ions.

BULL and BREESE (2) proposed six water molecules are bound to the polar side chains with the exception of the amides which were assigned a value of -7 . Such a result would correspond to a large value of $\mathrm{B}_{3}$, salt-binding, in the EISENBERG model (14).

KUNTZ (11) has shown by NMR studies of polypeptides that the hydration of ionic residues ranges from 3 to 7 water molecules whereas the non-polar side chains display hydrations between 1 and 4 .

\section{ACKNOWLEDGEMENTS}

The authors are indebted to Professor MARTIN OTTESEN for numerous and helpful conversations during both the experimental and writing stages of preparing this manuscript. The authors are pleased to acknowledge the excellent assistance of LISBETH SEJERSEN in the design of the computor program and wishes to thank Dr. STEPhEN Bayne, Dr. IB SVEndSEN and Dr. D. SHARP for their critical reviewing of the manuscript. Torben Graves Pedersen gratefully acknowledges financial and travel support from the National Institutes of Health and the Carlsberg Laboratory. This work was supported in part by Research Grant No. GM18871 from the National Institute of General Medical Sciences of the United States Public Health Service. JAMES B. IFFT is indebted to the Carlsberg Laboratory for financial support and to the University of Redlands, Redlands, California, for providing a sabbatical leave for the 1976-1977 academic year when a portion of this work was completed.

\section{REFERENCES}

1. Breuer, M. M. \& M. G. Kennerley: The hydration of synthetic polypeptides. J. Colloid Interface Sci. 37, 124-131 (1971)

2. Bull, H. B. \& K. Breese: Protein hydration. I. Binding sites. Arch. Biochem. Biophys, 128, 488496 (1968)

3. BULL, H. B. \& K. BREESE: Binding of water and electrolytes to proteins. An equilibrium dialysis study. Biopolymers 15, 1573-1583 (1976)

4. Ellis, D. A., V. Coffman \& J. B. IfFT: The buoyant titration of native and carbamylated bovine serum mercaptalbumin. Biochemistry. 14, 1205-1210(1975)

5. Falk, M., A. G. PoOle \& C. G. Goymour: Infrared study of the state of water in the hydration shell of DNA. Can. J. Chem. 48, 1536-1542 (1970)

6. Hearst, J. E.: Determination of the dominant factors which influence the net hydration of native sodium deoxyribonucleate. Biopolymers 3 , 57-68 (1965)

7. Hearst, J. E. \& J. Vinograd: The net hydration of T-4 bacteriophage deoxyribonucleic acid and the effect of hydration on buoyant behaviour in a density gradient at equilibrium in the ultracentrifuge. Proc. Nat. Acad. Sci., U.S. 47, 1005-1014 (1961)

8. IFFT, J. B.: Proteins at sedimentation equilibrium in density gradient. In: A laboratory manual of analytical methods of protein chemistry. 5,151 223 , edited by Alexander $O$. and K. P. Lundgren, Pergamon Press, New York (1969)

9. IFFT, J. B.: The buoyant titration of native and carbamylated ovalbumin. Compt. Rend. Trav. Lab. Carlsberg. 38, 315-338 (1971)

10. Ifft, J. B., W. R. Martin, III \& K. Kinzie: Density gradient proportionality constants for a number of aqueous binary solutions. Biopolymers 9: 597-614 (1970)

11. KUNTZ, I. D.: Hydration of macromolecules. III. Hydration of polypeptides. J. A m. Chem. Soc. 93, 514-516 (1971)

12. Marshall, R. D. \& A. Neuberger: Hen's egg albumin. In: Glycoproteins, BBA p. $736 \mathrm{ed}$. by Alfred Gottschalk (1972)

13. Martin, R. B.: Introduction to biophysical chemistry, p. 79, McGraw-Hill (1964)

14. Reisler, E., Y. Haik \& H. EISEnberg: Bovine serum albumin in aqueous guanidine hydrochloride solutions. Preferential and absolute interactions and comparison with other systems. Biochem. 16, 197-203 (1977)

15. Robinson, R. A. \& R. H. Stokes: Electrolyte solutions, p. 485, Academic Press (New York) (1955) 
16. RUARK, J. E. \& J. B. IFFT: The buoyant and potentiometric titrations of human immunogamma globulin. Biopolymers 14, 1161-1171 (1975)

17. Sharp, D. S., R. Almassy, L. G. Lum, K. Kinzie, J. S. V. ZIL \& J. B. IFFT: Buoyant and potentiometric titrations of synthetic polypeptides. II. Five copolypeptides and two nonionizable homopolypeptides in $\mathrm{CsCl}$ solutions. Biopolymers 15, 757-783 (1976)

18. SHARP, D. S. \& J. B. IFFT: An improved method of computation of density distributions. Biopolymers 16, 1153-1158 (1977)

19. SVENDSEN, I.: Buoyant titration of bovine mercaptalbumin chemically modified at the carboxyl groups. Carlsberg Res. Commun. 41, 111-120 (1976)
20. Sørensen, S. P. L. \& M. Høyrup: Protein studies I. The preparation of egg albumin solution with well-defined composition and the analytical methods employed. Compt. Rend. Trav. Lab. Carlsberg. 12, †2-67 (1916)

21. TunIS, M. J. B. \& J. E HEARST: On the hydration of DNA I. Preferential hydration and stability of DNA in concentrated trifluoroacetate solution. Biopolymers 6, 1325-1344 (1968)

22. Williams, A. E. \& J. B. IFFT: The buoyant titration of bovine serum mercaptalbumin. Biochim. Biophys. Acta, 131, 311-318 (1969)

23. ZIL, J. S. V. \& J. B. IFFT: Buoyant titrations of conalbumin, cytochrome-C, and myoglobin. Unpublished observations. 